\title{
Cas d'infection à virus Zika au Canada liés à des voyages : octobre 2015 à juin 2017
}

\author{
J Tataryn ${ }^{1 *}$, L Vrbova², M Drebot ${ }^{3}$, H Wood $^{3}$, E Payne ${ }^{4}$, S Connors², J Geduld ${ }^{4}$, M German', \\ K Khan ${ }^{5,6}$, PA Buck ${ }^{7}$
}

\section{Résumé}

Contexte : Le virus Zika est une maladie émergente transmise par des moustiques qui peut causer de graves anomalies congénitales lorsqu'elle est contractée par voie congénitale. Depuis la fin de 2015, il y a eu une augmentation marquée du nombre de cas d'infection à virus Zika liés au voyage au Canada.

Objectif : La présente étude avait pour objectif de décrire l'épidémiologie des cas de virus Zika liés au voyage au Canada d'octobre 2015 à juin 2017 et de les examiner dans le contexte de l'éclosion internationale dans les Amériques.

Méthodologie : Les infections à virus Zika ont été confirmées par détection de l'ARN viral au moyen d'une réaction en chaîne de la polymérase ou par identification sérologique d'anticorps spécifiques au virus ZIKA dans le sérum. Les cas d'infection ont été repérés par les autorités sanitaires provinciales et territoriales et déclarés de façon régulière à l'Agence de la santé publique du Canada (ASPC). Les renseignements demandés sur les cas comprenaient la date d'apparition de la maladie, le groupe d'âge, le sexe, l'état de grossesse, ainsi que la ou les destinations et les dates de voyage. Les estimations du nombre de Canadiens par mois qui voyagent dans d'autres pays des Amériques ont été obtenues de Statistique Canada et de l'Association du transport aérien international. Les données pour produire les courbes épidémiques de cas autochtones pour chaque région des Amériques ont été extraites des courbes épidémiques propres à chaque pays sur le site Web de l'Organisation panaméricaine de la santé.

Résultats : Au 7 juin 2017, 513 cas confirmés en laboratoire et deux cas d'anomalies fœtales ou à la naissance liées au virus Zika ont été déclarés dans les dix provinces. L'apparition de la maladie chez les voyageurs canadiens coïncidait généralement avec l'intensité de l'éclosion dans le pays d'exposition plutôt qu'avec le nombre de voyages. On n'a relevé aucune preuve de transmission autochtone (locale) au Canada. Le nombre de cas signalés est actuellement en baisse tant au Canada qu'à l'échelle internationale.

Conclusion : La montée subite du nombre de cas d'infections à Zika observée en 2016 était directement liée à l'incursion et à la propagation du virus dans les Amériques. Bien que le nombre de cas soit maintenant à la baisse partout dans le monde, il reste à voir s'il se produira une résurgence dans les régions touchées précédemment. On devrait surveiller, au fil du temps, à la fois l'intensité des éclosions et le caractère saisonnier de la transmission du virus en vue de choisir les meilleures dates possibles pour les campagnes de sensibilisation puisque certaines seront probablement plus efficaces pendant les périodes creuses quand le risque de transmission est peut-être plus élevé. On continue de recommander l'information et la sensibilisation constante des voyageurs, en particulier les femmes enceintes et celles qui prévoient de tomber enceintes.

\section{Affiliations}

${ }^{1}$ Centre des maladies infectieuses d'origine alimentaire, environnementale et zoonotique, Direction générale de la prévention et du contrôle des maladies infectieuses, Agence de la santé publique du Canada, Saskatoon (Saskatchewan)

${ }^{2}$ Centre des maladies infectieuses d'origine alimentaire, environnementale et zoonotique, Direction générale de la prévention et du contrôle des maladies infectieuses, Agence de la santé publique du Canada, Toronto (Ontario)

${ }^{3}$ Laboratoire national de microbiologie, Direction générale de la prévention et du contrôle des maladies infectieuses, Agence de la santé publique du Canada, Winnipeg (Manitoba)

${ }^{4}$ Bureau des services de santé à la frontière, Direction générale de l'infrastructure de sûreté sanitaire, Agence de la santé publique du Canada, Ottawa (Ontario)

${ }^{5}$ Faculté de médecine, Division des maladies infectieuses, Université de Toronto, Toronto (Ontario)

${ }^{6}$ Institut de connaissances Li Ka Shing, Hôpital St. Michael, Toronto (Ontario)

${ }^{7}$ Centre des maladies infectieuses d'origine alimentaire, environnementale et zoonotique (CMIAEZ), Direction générale de la prévention et du contrôle des maladies infectieuses, Agence de la santé publique du Canada, Ottawa (Ontario)

*Correspondance: joanne.tataryn@ canada.ca

Citation proposée : Tataryn J, Vrbova L, Drebot M, Wood H, Payne E, Connors S, Geduld J, German M, Khan K, Buck PA. Cas d'infections à virus Zika au Canada liés à des voyages : octobre 2015 à juin 2017. Relevé des maladies transmissibles au Canada. 2018;44(1):21-9. https://doi.org/10.14745/ccdr.v44i01a05f

\section{Introduction}

Le virus Zika est un flavivirus véhiculé principalement par les moustiques et transmis aux êtres humains par les moustiques du genre Aedes. D'abord identifié en 1947 dans la forêt Zika en Ouganda $(1,2)$, le virus Zika est resté largement confiné pendant plus de 50 ans dans une ceinture équatoriale relativement étroite s'étendant de l'Asie à l'Afrique (3). En 2007, la première éclosion majeure du virus a été signalée à Yap, une île de Micronésie (4), suivie de plusieurs éclosions dans les îles et archipels du Pacifique, dont une vaste éclosion en Polynésie française en $2013(5,6)$. Il a été signalé au Brésil en 2015 et s'est depuis propagé en Amérique centrale, en Amérique du Sud, dans les Antilles et au Mexique. Cette éclosion était accompagnée d'une augmentation alarmante du nombre de bébés nés de mères infectées et atteints de microcéphalie et d'autres troubles 
neurologiques. À la suite de cette constatation, l'Organisation mondiale de la santé (OMS) a déclaré une urgence de santé publique de portée internationale (USPPI) le $1^{\text {er }}$ février 2016, et demandé une intervention et une collaboration internationales (7).

Le virus Zika se propage principalement par la piqûre d'un moustique infecté, mais il peut également se transmettre par voie verticale intra-utérine, sexuellement et par le sang (8-14). On estime que seulement $20 \%$ des personnes infectées par le virus présenteront des symptômes (4). Si des symptômes se manifestent, ils apparaissent habituellement trois à sept jours (maximum 14 jours) après l'infection et peuvent inclure une légère fièvre, de l'arthrite, de l'arthralgie, une éruption maculo-papuleuse, de la conjonctivite, de la myalgie et d'autres symptômes grippaux non spécifiques $(4,15)$. L'infection peut ne pas être reconnue ou méprise pour la dengue, le chikungunya ou une autre infection virale causant de la fièvre et des éruptions cutanées. Des complications neurologiques comme le syndrome de Guillain-Barré ont déjà été signalées, bien que rarement (16).

La plus grande préoccupation liée à ce virus a trait aux graves répercussions qu'il peut avoir sur le fœtus en développement, puisqu'il peut causer un large éventail d'anomalies congénitales connues sous le nom de syndrome de Zika. Si des anomalies du cerveau et la microcéphalie sont couramment signalées $(17,18)$, le syndrome de Zika peut également causer de l'arthrogrypose (une mobilité réduite de plusieurs articulations due à des contractures), de la dysphagie (difficulté à avaler), des déficiences auditives et visuelles et d'autres anomalies (19). Selon le registre de grossesses à virus Zika des États-Unis, environ $5 \%$ (intervalle de confiance de $95 \%[\mathrm{IC}]=4 \%$ à $7 \%$ ) des grossesses menées à terme et assorties de données de laboratoire indiquant une récente infection possible à virus Zika (exposition récente à un flavivirus) s'étaient soldées par des signes d'infection chez le fœtus ou le bébé. Cette proportion a augmenté à $10 \%$ (IC de $95 \%=7 \%$ à $14 \%$ ) lorsqu'on ne tenait compte que des grossesses pour lesquelles une infection à virus Zika avait été confirmée par un laboratoire et $15 \%$ (IC de $95 \%=8 \%$ à $26 \%$ ) des fœtus et des bébés de grossesses menées à terme présentaient au premier trimestre une infection confirmée (17). Les infections symptomatiques et asymptomatiques pendant la grossesse semblent toutes livrer des pourcentages semblables en ce qui concerne les anomalies congénitales $(17,18)$.

Avant 2015, seulement un cas d'infection à virus Zika confirmé en laboratoire avait été signalé au Canada - chez un voyageur revenant de la Thaïlande (20). En décembre 2015, le Canada a recensé son tout premier cas lié à un voyage et à l'éclosion dans les Amériques (21). Jusqu'ici, aucune transmission locale n'a été signalée, étant donné que les principaux moustiques vecteurs - Aedes aegypti et Aedes albopictus - ne sont pas établis ici. Bien que la transmission locale par des moustiques au Canada soit improbable, les Canadiens effectuent environ 7,3 millions de voyages dans les Antilles, en Amérique centrale, en Amérique du Sud et au Mexique chaque année, sans compter de nombreux voyages vers les régions d'Asie, du Pacifique et d'Afrique où le virus continue de circuler (22). Au 29 juin 2017,56 pays ou régions ont signalé une introduction ou une réintroduction du virus Zika depuis 2015 et 20 autres ont signalé des cas d'infection avant 2015 et une transmission continue (23). Plusieurs pays signalent une baisse du nombre de cas; d'autres continuent toutefois d'enregistrer des hausses à ce chapitre (24).
La persistance et la recirculation du virus Zika à mesure que l'immunité se développe, ainsi que les changements saisonniers dans l'activité des vecteurs sont largement inconnus et donnent lieu à des préoccupations continues (25). Le gouvernement du Canada a réagi à la propagation du virus en émettant des Conseils de santé aux voyageurs, recommandant aux femmes enceintes et à celles qui prévoient de le devenir d'éviter de se rendre dans des pays où les éclosions de virus Zika continuent de sévir (26). De plus, le Comité consultatif de la médecine tropicale et de la médecine des voyages (CCMTMV) a élaboré les Recommandations sur la prévention et le traitement du virus Zika dans le but d'informer les professionnels de la santé canadiens des risques liés au Zika et de leur fournir des recommandations sur la manière de réduire ces risques (27).

À la suite de la déclaration d'une USPPI par l'OMS, des partenaires fédéraux, provinciaux et territoriaux canadiens ont convenu de mettre en place un système national de déclaration des cas de Zika à titre temporaire afin de :

- Se conformer aux exigences de déclaration du Règlement sanitaire international

- Maintenir une connaissance situationnelle du contexte au Canada, y compris l'évaluation des endroits où les infections se produisent et du mode de transmission probable

- Évaluer le niveau de risque pour la population canadienne et en informer cette dernière dans la mesure du possible

- Contribuer au développement des connaissances sur le virus Zika à l'échelle internationale

Le présent article décrit l'épidémiologie des cas de virus Zika au Canada liés à des voyages d'octobre 2015 à juin 2017 et les examine dans le contexte de l'éclosion internationale dans les Amériques.

\section{Méthodologie}

\section{Diagnostic en laboratoire}

La confirmation des infections à virus Zika s'effectue principalement au moyen de deux méthodologies d'essai : la détection de I'ARN viral dans le sérum grâce à une réaction en chaîne de la polymérase (PCR) ou des échantillons d'urine et l'identification sérologique d'anticorps spécifiques au virus Zika dans le sérum (27-29). Des échantillons de sérum et d'urine en phase aiguë (recueillis dans les deux semaines suivant l'apparition des symptômes) sont les spécimens les plus appropriés pour les tests de PCR étant donné que la virémie tend à être éphémère et que le virus n'est habituellement présent dans ces échantillons que durant un court laps de temps. Le dosage immunoenzymatique (ELISA) est le principal test de dépistage sérologique utilisé pour détecter les expositions ou les cas possibles d'infection par détection d'anticorps viraux de l'immunoglobuline M (lgM) et de l'immunoglobuline G (lgG). Toutefois, en raison de la réactivité croisée avec d'autres virus apparentés comme la dengue, il faut également effectuer un essai de séroneutralisation par réduction des plages de lyse en vue de détecter les anticorps spécifiques au virus Zika dans les échantillons positifs par ELISA. Les anticorps du virus Zika se développent habituellement trois à cinq semaines après l'exposition et peuvent être détectés pendant plusieurs mois (lgM) ou années (lgG neutralisants). Dans certains cas, les patients ont peut-être déjà été exposés à d'autres flavivirus 
à la suite de vaccins ou de piqûres de moustiques (p. ex., fièvre jaune, vaccins contre le virus de l'encéphalite japonaise), ce qui peut causer d'autres complications au moment de I'interprétation des résultats sérologiques. Des titres de neutralisation sériques élevés à la fois pour le virus de la dengue et le virus Zika peuvent être détectés dans les échantillons prélevés chez certaines personnes (par ex., infections secondaires à flavivirus), ce qui peut entraîner la documentation de ces cas comme étant une "exposition à des flavivirus " sans aucune identification certaine du virus responsable de l'infection.

Initialement, tous les tests en laboratoire ont été effectués au Laboratoire national de microbiologie (LNM); toutefois, les laboratoires de santé publique de la Colombie-Britannique, de l'Alberta, de l'Ontario et du Québec ont adopté le test PCR sur leurs territoires respectifs. Les initiatives de dépistage visent principalement les femmes enceintes et les voyageurs symptomatiques. Les tests sérologiques sont actuellement effectués au LNM; toutefois, des tests IgM et IgG ELISA sensibles sont maintenant disponibles sur le marché et permettront à certains laboratoires provinciaux d'ajouter les tests de dépistage à leur gamme de tests de diagnostic.

\section{Épidémiologie}

Un cas d'infection à virus Zika a été recensé chez un Canadien et confirmé en laboratoire par un ou plusieurs des tests suivants, avec ou sans preuves cliniques: 1) isolation du virus ou détection de l'antigène viral ou de l'acide nucléique spécifique d'un spécimen clinique approprié; ou 2) des anticorps de l'IgM virale contre le virus Zika dans un spécimen clinique approprié et l'identification d'anticorps de confirmation neutralisants spécifiques au virus dans le même échantillon ou dans un échantillon ultérieur, ou une augmentation (quadruple ou plus) démontrée de séroconversion ou de diagnostics dans les titres d'anticorps neutralisants spécifiques au virus dans les sérums appariés.

Les cas d'infection à virus Zika ont été repérés par les autorités sanitaires provinciales et territoriales et déclarés de façon régulière à l'Agence de la santé publique du Canada (ASPC). Les renseignements demandés sur les cas comprenaient la date d'apparition de la maladie, le groupe d'âge, le sexe, l'état de grossesse, ainsi que la ou les destinations et les dates de voyage.

On a estimé la date d'exposition pour les cas en utilisant la date de retour du voyage ou la date d'apparition de la maladie moins sept jours si la date de retour n'était pas disponible. Aucune date d'exposition n'a été fixée pour les voyageurs qui ont visité plusieurs pays ou ceux pour qui aucune des deux dates susmentionnées n'était disponible. Pour chaque cas, l'état de l'éclosion dans le pays de destination a été déterminé d'après la courbe épidémique pour le pays au moment de l'exposition du voyageur. La " période d'éclosion » ou période de "forte activité " pour chaque pays a été désignée comme le moment où les cas ont commencé à augmenter de façon marquée (souvent trois fois plus de cas ou plus) par rapport au nombre initial de cas signalés, jusqu'au moment où le nombre de cas est revenu à un niveau semblable au nombre de cas signalés initialement. La période précédant la première éclosion a été désignée comme une période de "faible activité " ou d' "éclosion précoce. " Toutes les autres périodes, que ce soit entre les vagues d'éclosions ou à la fin de l'épidémie, étaient considérées comme des périodes de "faible activité ».

Les estimations du nombre de Canadiens qui voyagent chaque mois dans d'autres pays des Amériques ont été obtenues de deux sources : les statistiques annuelles sur le nombre de voyageurs vers des régions et pays précis ont été obtenues de l'Enquête sur les voyages internationaux de Statistique Canada, 2015 (22) et les statistiques sur le nombre de voyageurs mensuels pour les Amériques en 2015 et en 2016 ont été obtenues en utilisant les données sur les ventes de billets de passagers de l'Association du transport aérien international (IATA). Les données de I'IATA comprennent les itinéraires complets des voyageurs, y compris leur aéroport d'embarquement initial, leur aéroport de destination et, s'il y a lieu, les aéroports d'escale. Ces données représentent environ $90 \%$ de tous les voyages effectués sur les vols commerciaux dans le monde entier; les autres $10 \%$ sont modélisés en utilisant les informations commerciales du marché du transport aérien. On a estimé les chiffres pour 2017 en utilisant une moyenne des valeurs mensuelles de 2015 et de 2016.

Les données pour produire les courbes épidémiques de cas autochtones pour chaque région des Amériques ont été extraites des courbes épidémiques propres à chaque pays sur le site Web de l'Organisation panaméricaine de la santé (24) en utilisant I'outil WebPlotDigitizer. Les pays utilisés dans ces estimations sont les suivants :

- Amérique du Nord : Mexique

- Antilles : Anguilla, Antigua-et-Barbuda, Aruba, Barbade, Curaçao, Dominique, République dominicaine, Bonaire, Saint-Eustache, îles Caïmans, Grenade, Guadeloupe, Haïti, Jamaïque, Martinique, Montserrat, Porto Rico, Saint-Barthélemy, Saint-Kitts-et-Nevis, Saint-Martin, Saint-Vincent-et-Grenadines, Saint Maarten, îles Vierges américaines, Saint-Thomas, Sainte-Croix, Saint-Jean, Trinité-et-Tobago, îles Turques et Caïques

- Amérique centrale : Bélize, Costa Rica, El Salvador, Guatemala, Honduras, Nicaragua, Panama

- Amérique du Sud: Argentine, Bolivie, Brésil, Colombie, Équateur, Guyane française, Guyane, Paraguay, Pérou, Surinam et Vénézuela

\section{Résultats}

Entre mai 2015 et le 7 juin 2017, plus de 22000 échantillons ont été testés par le LNM. Le nombre d'échantillons reçus chaque semaine a augmenté de façon spectaculaire vers la sixième semaine (du 7 au 13 février 2016). Depuis lors, les volumes de tests sont demeurés élevés, avec une moyenne de 320 échantillons soumis chaque semaine (plage : 165 à 500 échantillons par semaine), même si le nombre d'échantillons positifs diminue (figure 1).

Au 7 juin 2017, il y a eu 513 cas de Zika confirmés dans les dix provinces. Des renseignements sur le mode de transmission étaient disponibles pour 512 cas et, parmi ceux-ci, 507 (99\%) ont contracté l'infection lors de voyages dans les régions touchées. Trois autres cas non liés à des voyages étaient dus à des relations sexuelles avec un voyageur infecté. Deux $(n=2)$ cas de transmission de la mère au fœtus ont été signalés. 
Figure 1 : Nombre et pourcentage de patients infectés par le virus Zika testés par le Laboratoire national de microbiologie, Canada, janvier 2015 à juin 2017ª

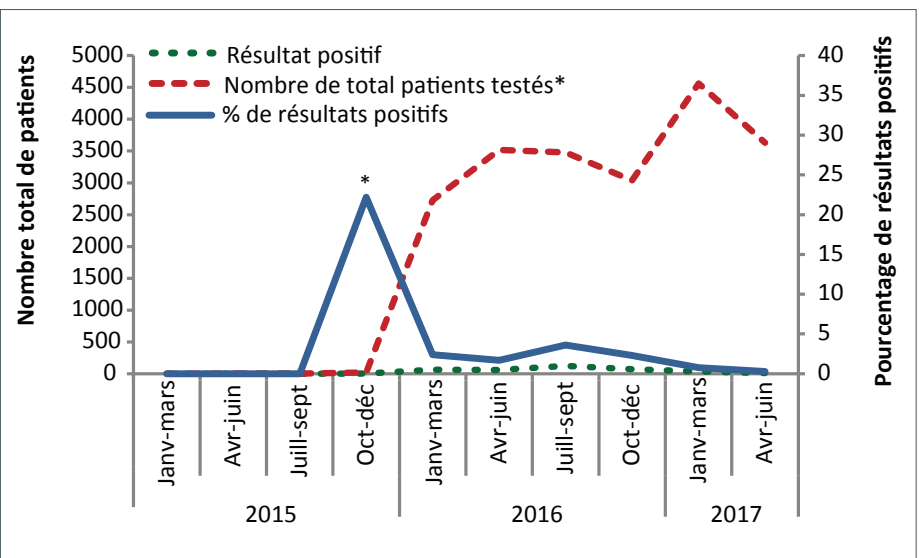

a Entre octobre et décembre 2015, 18 échantillons ont été testés; de ce chiffre, quatre (22\%) étaient positifs

Cinquante-cinq pour cent (55\%) des personnes infectées avaient de 20 à 44 ans, et $64 \%$ d'entre elles étaient des femmes (tableau 1).

Tableau 1 : Cas confirmés par groupe d'âge et sexe, Canada, octobre 2015 à juin 2017

\begin{tabular}{|l|r|r|r|r|}
\hline \multicolumn{1}{|c|}{$\begin{array}{c}\text { Âge } \\
\text { (années) }\end{array}$} & Femmes & Hommes & $\begin{array}{c}\text { Sexe } \\
\text { inconnu }\end{array}$ & \multicolumn{1}{c|}{$\begin{array}{c}\text { Total (\% du } \\
\text { Total) }\end{array}$} \\
\hline $\begin{array}{l}\text { Nouveau } \\
\text { né à } 1 \text { an }\end{array}$ & 2 & 0 & 0 & 2 (moins de 1\%) \\
\hline 1 à 19 ans & 13 & 9 & 0 & $22(4 \%)$ \\
\hline 20 à 44 ans & 195 & 86 & 0 & $281(55 \%)$ \\
\hline 45 à 64 ans & 96 & 69 & 6 & $171(33 \%)$ \\
\hline $\begin{array}{l}\text { Plus de } 64 \\
\text { ans }\end{array}$ & 20 & 17 & 0 & $37(7 \%)$ \\
\hline $\begin{array}{l}\text { Total }(\% \text { du } \\
\text { Total) }\end{array}$ & $326(64 \%)$ & $181(35 \%)$ & $6(1 \%)$ & $513(100 \%)$ \\
\hline
\end{tabular}

Parmi les cas pour lesquels des renseignements étaient disponibles $(n=499), 99$ \% ( $n=492)$ ont signalé des symptômes avant les tests de dépistage. Les dates d'apparition de la maladie allaient du 12 octobre 2015 au 30 mars 2017, avec une pointe observée en juillet et en août 2016 (figure 2). Trente-cinq (35) grossesses ont été déclarées parmi les femmes infectées par le virus; toutefois, l'issue de ces grossesses n'a pas fait l'objet d'un suivi systématique et les données disponibles sont donc limitées. Parmi les quatre grossesses dont l'issue a fait l'objet d'un suivi, deux bébés n'avaient aucune anomalie apparente à la naissance et deux fœtus ou nourrissons présentaient des anomalies liées au virus Zika.

Dans l'ensemble, $66 \%$ des voyageurs canadiens ont été infectés lorsqu'ils étaient en voyage dans les Antilles, $19 \%$ l'ont été en Amérique centrale, $10 \%$ en Amérique du Nord (Mexique) et $6 \%$ en Amérique du Sud (annexe 1).

Dans la plupart des cas ( $83 \%)$, les voyageurs s'étaient rendus dans leurs pays de destination au moment où ces derniers recensaient un nombre élevé de cas (pendant la période d'« éclosion »); cependant, il y a eu certains cas où le voyageur
Figure 2 : Nombre de cas d'infection à virus Zika liés à des voyages selon le mois d'apparition des symptômes et la région de destination, Canada, octobre 2015 à juin $2017(n=334)^{a}$

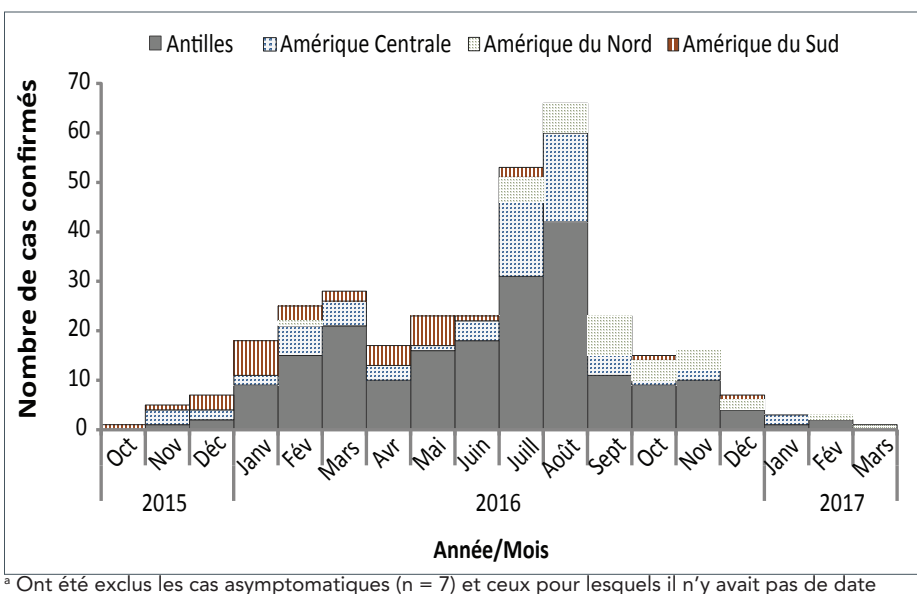
d'apparition de la maladie $(n=172)$

avait visité le pays de destination avant que celui-ci ne signale un premier cas d'infection (2\%) ou pendant les périodes d'activité plus faible (16\%) (tableau 2).

Tableau 2 : Date du voyage par rapport à l'état d'éclosion de Zika dans le pays de destination : Canada, 2015 à 2017

\begin{tabular}{|c|c|c|}
\hline $\begin{array}{c}\text { État de l'épidémie dans le pays de } \\
\text { destination }\end{array}$ & $\begin{array}{l}\text { Nombre } \\
\text { de cas }\end{array}$ & $\begin{array}{c}\% \text { du } \\
\text { nombre } \\
\text { total de } \\
\text { cas }\end{array}$ \\
\hline Avant la déclaration du premier cas & 5 & 2 \\
\hline Faible activité : tôt dans l'éclosion & 16 & 6 \\
\hline $\begin{array}{l}\text { Activité élevée : pendant la principale } \\
\text { période d'éclosion: }\end{array}$ & 240 & 83 \\
\hline $\begin{array}{l}\text { Faible activité : vers la fin de la période } \\
\text { d'éclosion ou entre les vagues d'éclosions }\end{array}$ & 28 & 10 \\
\hline Total & 289 & 100 \\
\hline
\end{tabular}

Le profil des cas liés à des voyages semble coïncider davantage avec l'activité de transmission du virus Zika dans la région, plutôt que le nombre de voyageurs en provenance du Canada (figure 3).

Figure 3 : Profil de voyages mensuels et cas canadiens d'infection à virus Zika selon la région de destination

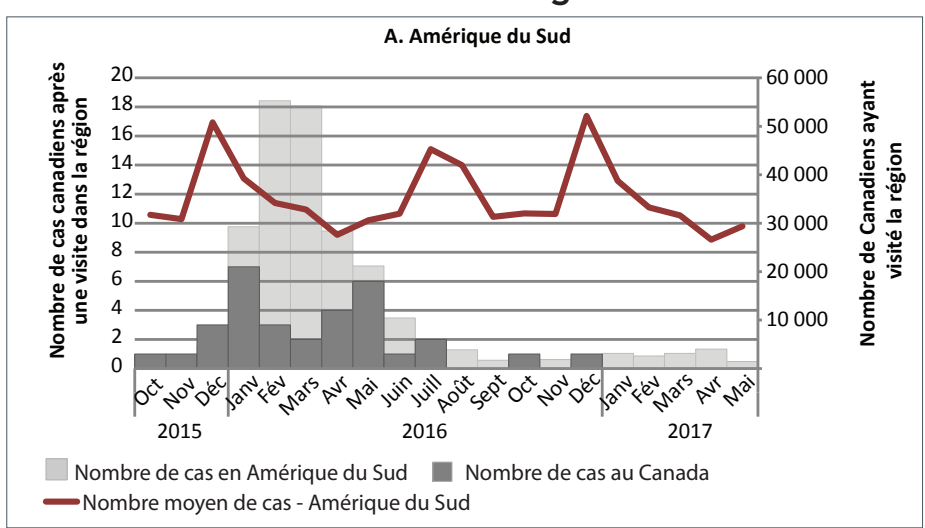

RMTC・Le 4 janvier $2018 \bullet$ Volume 44-1

Page 24 
Figure 3 : Profil de voyages mensuels et cas canadiens d'infection à virus Zika selon la région de destination (suite)
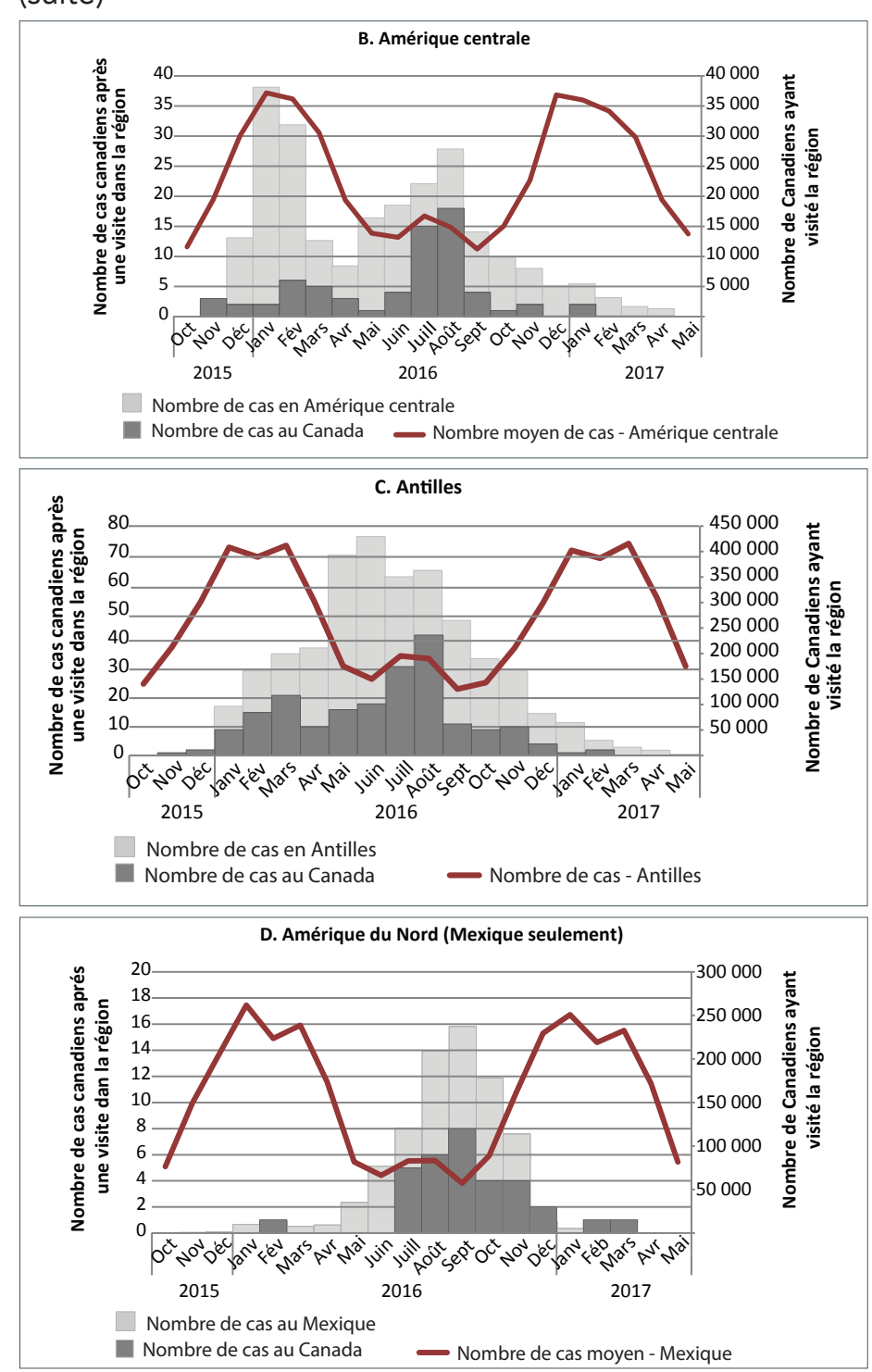

N.B. : Profils de voyages (ligne rouge) et cas canadiens (barres gris foncé) par région de destination, avec profil de cas endémiques dans la région (barres gris clair). La droite verticale de gauche représente le nombre de cas canadiens; la droite verticale de droite représente le nombre estimatif de personnes en provenance du Canada qui visitent la région, d'après les données mensuelles sur les voyages de l'IATA. Pour le nombre estimatif de cas endémiques par région, le profil de la courbe épidémique régionale est indiqué, sans échelle

\section{Discussion}

Entre octobre 2015 et juin 2017, on a recensé 507 cas confirmés d'infection à virus Zika liés à des voyages et trois cas de transmission sexuelle au Canada. Soixante-quatre pour cent des personnes infectées étaient des femmes et, de ce nombre, $11 \%$ étaient enceintes. La constatation d'un nombre plus élevé de femmes infectées que d'hommes va dans le sens d'autres rapports internationaux et reflète probablement un biais dans le dépistage et la déclaration plutôt que des différences biologiques touchant la susceptibilité ou l'exposition (30). Les renseignements sur les résultats étaient disponibles pour seulement quatre grossesses : deux fœtus ou bébés présentaient des anomalies liées au Zika et deux n'avaient aucune anomalie apparente.
Malgré la baisse du nombre de cas chez les voyageurs de retour au pays dans les derniers mois, le volume de tests de dépistage en laboratoire demeure élevé, ce qui reflète des préoccupations continues chez les couples qui attendent un bébé et ceux qui planifient une grossesse. On continue d'observer un nombre significatif de femmes enceintes « inquiètes": celles qui ont visité une région à risque et n'ont manifesté aucun symptôme, mais qui ont subi un test de dépistage. Étant donné que les infections symptomatiques et asymptomatiques semblent toutes livrer des pourcentages semblables en ce qui concerne les anomalies congénitales, ces inquiétudes sont tout à fait justifiées. À mesure que les taux d'infection continuent de baisser, il y a d'entrée de jeu une très faible probabilité d'infection lorsque le test est administré à des personnes asymptomatiques, ce qui limite la valeur du dépistage. Par conséquent, les directives sur le dépistage ne recommandent pas de tester de façon systématique les femmes enceintes asymptomatiques qui ne courent aucun risque continu (les voyageuses) (31). Plusieurs procédures de dépistage sont disponibles pour le repérage des cas; toutefois, les réactions croisées d'anticorps entre le Zika et les virus apparentés comme la dengue peuvent compliquer le diagnostic lorsqu'on utilise des plateformes sérologiques. Également, les personnes qui ont déjà été exposées à des flavivirus apparentés peuvent présenter des réactions sérologiques susceptibles de brouiller l'interprétation des tests. Par conséquent, certaines expositions au virus Zika ne peuvent pas être confirmées par immuno-essai et sont consignées comme étant des "infections à Flavivirus ». Dans ces cas, les médecins devraient savoir qu'une exposition au virus Zika a tout de même pu se produire.

Presque tous les cas recensés au Canada étaient liés à des voyages et il n'y a jusqu'à présent aucune preuve de transmission autochtone. Les données suggèrent qu'il est peu probable que la transmission sexuelle à elle seule déclenche une éclosion (30) et la transmission continue est peu probable en l'absence des moustiques tropicaux ou subtropicaux du genre Aedes (32). Les principaux moustiques vecteurs - Aedes aegypti et Aedes albopictus - ne sont pas établis au Canada et la recherche actuelle suggère que les espèces de moustiques canadiennes ne constituent pas des hôtes compétents. De plus, on estime que le risque de transmission autochtone par l'établissement de moustiques Aedes albopictus est très faible, étant donné les conditions climatiques actuelles.

L'apparition de la maladie chez les voyageurs canadiens coïncidait généralement avec l'intensité de l'éclosion dans le pays d'exposition plutôt qu'avec le nombre de voyages. On a déjà souligné que le risque pour les voyageurs varie selon la force des cycles de transmission dans les pays de destination et que les voyageurs en tant que groupe ne jouissent pas d'une protection spéciale contre l'infection dans les pays touchés du simple fait d'être en voyage (32). Les pointes dans les cas recensés en juillet et en août 2016 étaient dues à l'augmentation du nombre d'expositions en Amérique centrale et dans les Antilles et, dans une certaine mesure, au Mexique, mais à une période où les voyages vers ces destinations sont habituellement à un bas niveau saisonnier. On a démontré que les facteurs climatiques comme la température, l'humidité et les précipitations influencent l'abondance des vecteurs et, en fin de compte, le degré de transmission des maladies comme la dengue et le chikungunya (33), ce qui entraîne des tendances de transmission saisonnière favorisant les mois plus chauds et les plus humides. On devrait surveiller, au fil du temps, à la fois l'intensité des éclosions et le caractère saisonnier de la transmission du virus en vue de choisir les meilleures dates 
possibles pour les campagnes de sensibilisation puisque certaines seront probablement plus efficaces pendant les périodes creuses quand le risque de transmission de maladies est peut-être plus élevé, même si le nombre absolu de voyages est plus faible.

\section{Limitations}

Il y a plusieurs limitations qui valent la peine d'être notées lorsqu'on interprète les résultats. Les résultats des tests en laboratoire présentés ici ne représentent que seulement un sous-ensemble des tests de dépistage effectués au Canada. Bien que tous les tests de dépistage aient été effectués à l'origine par le LNM, à mesure que l'épidémie progressait, trois provinces ont adopté le dépistage par PCR pour le Zika sur leur territoire respectif. Les constatations rapportées ici sous-estiment le volume total de tests de dépistage du Zika effectués au Canada.

Deuxièmement, les dates d'apparition de la maladie n'étaient pas disponibles pour un certain nombre de cas, et ont donc été exclues de la courbe épidémique. Pour déterminer l'incidence de l'exclusion de ces cas, on a comparé ceux pour lesquels il y avait des renseignements disponibles et ceux pour lesquels il n'y en avait pas. Des dates d'apparition approximatives ont été générées pour les cas pour lesquels ces dates n'étaient pas disponibles, en utilisant la date de confirmation par PCR et en tenant compte des délais moyens de dépistage et de déclaration. $\mathrm{D}^{\prime}$ après cette analyse, on a observé une certaine variabilité dans le moment de l'infection pour les cas pour lesquels on n'avait pas de date d'apparition de la maladie; ces moments coïncidaient cependant avec les pointes de la courbe épidémique. Bien que le fait d'exclure ces cas ait entraîné une légère atténuation des pointes, la forme générale de la courbe est demeurée la même et aucun autre changement significatif n'a été observé.

Les données sur l'issue des grossesses n'étaient pas recueillies de façon systématique aux fins de déclaration nationale; par conséquent, le très faible nombre de cas signalés ici devraient être interprétés avec précaution. On peut trouver des estimations plus fiables de l'incidence du virus Zika sur la grossesse ailleurs dans la documentation internationale.

\section{Conclusion}

Depuis la fin de 2015, il y a eu au Canada une augmentation significative du nombre de cas d'infection à virus Zika liés à des voyages. Étant donné que ce virus peut entraîner des symptômes semblables à ceux d'autres maladies virales et que beaucoup de personnes infectées peuvent présenter des symptômes légers ou ne présenter aucun symptôme, ces données constituent probablement une sous-estimation significative du nombre total de cas d'infection liés à des voyages chez les voyageurs qui reviennent au Canada à la suite de cette éclosion internationale dans les Amériques. Les cas au Canada et à l'échelle internationale sont maintenant à la baisse; toutefois, il est probable que des cas continuent d'être déclarés. L'incidence du caractère saisonnier et de l'immunité de la population sur la persistance du virus dans les Amériques et à plus grande échelle est inconnue. Il est important de continuer à surveiller l'intensité des éclosions et le caractère saisonnier de la transmission du virus dans les pays endémiques afin de choisir les meilleures dates possibles pour les campagnes de sensibilisation puisque certaines seront probablement plus efficaces pendant les périodes creuses quand le risque de transmission de maladies est peut-être plus élevé, même si le nombre absolu de voyages est plus faible.

Le virus du Zika est le troisième exemple d'un récent arbovirus émergent dans l'hémisphère occidental qui a une incidence significative sur la santé humaine (virus du Nil occidental, chikungunya). Une collaboration nationale et internationale soutenue est nécessaire pour se préparer à faire face à ces maladies émergentes. Une application plus poussée des nouvelles plateformes de diagnostic comme les tests de dépistage commerciaux ELISA contribuera à rehausser et à élargir les capacités de dépistage au Canada.

L'Agence santé publique du Canada et le CCMTMV recommandent que les femmes enceintes et celles qui planifient une grossesse devraient reporter tout projet de voyage vers les régions où le virus du Zika continue d'être transmis $(27,34)$. Les patients qui présentent des symptômes cliniques correspondant au Zika, ainsi que les femmes enceintes et les couples qui planifient une grossesse et qui sont récemment revenus d'un pays où le virus circule, devraient consulter leur fournisseur de soins de santé pour discuter de leur situation et des risques qu'ils courent. Les fournisseurs de soins de santé devraient continuer à sensibiliser leurs patients aux risques que pose le Zika et à les informer des mesures à prendre pour prévenir l'infection à virus Zika et d'autres infections transmises par les moustiques.

\section{Déclaration des auteurs}

J.T. - Conceptualisation, méthodologie, analyse, interprétation, rédaction de la première ébauche, examen et révision L.V. - Conceptualisation, méthodologie, analyse, interprétation, rédaction de la première ébauche (parties) et examen

M.D. - Conceptualisation, enquête, interprétation, rédaction de la première ébauche (parties) et examen

H.W. - Enquête, analyse, rédaction - examen

E.P. - Enquête, rédaction de la première ébauche (parties) et examen

S.C. - Enquête, rédaction de la première ébauche et examen J.J. - Enquête, conceptualisation, rédaction de la première ébauche (parties) et examen

M.G. - Méthodologie, analyse, rédaction de la première ébauche (parties) et examen

K.K. - Méthodologie, analyse, rédaction de la première ébauche (parties) et examen

P.A.B. - Conceptualisation, rédaction de la première ébauche, examen et révision

\section{Conflit d'intérêt}

Aucun.

\section{Remerciements}

Les auteurs aimeraient reconnaître les précieuses contributions de nos partenaires de l'épidémiologie et des laboratoires dans les provinces et les territoires qui ont participé à l'intervention à la suite de l'éclosion de Zika dans les Amériques. 


\section{Références}

1. Dick GW. Zika virus. II. Pathogenicity and physical properties. Trans R Soc Trop Med Hyg 1952 Sep;46(5):521-34. DOI (http://dx.doi.org/10.1016/0035-9203(52)90043-6). PubMed (https://www.ncbi.nlm.nih.gov/entrez/query.fcgi?cmd=Retrie ve\&db=PubMed\&list_uids=12995441\&dopt=Abstract).

2. Dick GW, Kitchen SF, Haddow AJ. Zika virus. I. Isolations and serological specificity. Trans R Soc Trop Med Hyg 1952 Sep;46(5):509-20. DOI (http://dx.doi.org/10.1016/00359203(52)90042-4). PubMed (https://www.ncbi.nlm.nih. gov/entrez/query.fcgi?cmd=Retrieve $\& d b=$ PubMed\&lis t_uids=12995440\&dopt=Abstract).

3. Song BH, Yun SI, Woolley M, Lee YM. Zika virus: History, epidemiology, transmission, and clinical presentation. J Neuroimmunol 2017 Jul;308:50-64. DOI (http://dx.doi. org/10.1016/j.jneuroim.2017.03.001). PubMed (https://www. ncbi.nlm.nih.gov/entrez/query.fcgi?cmd=Retrieve\&db=PubM ed\&list_uids=28285789\&dopt=Abstract).

4. Duffy MR, Chen TH, Hancock WT, Powers AM, Kool JL, Lanciotti RS et al. Zika virus outbreak on Yap Island, Federated States of Micronesia. N Engl J Med 2009 Jun;360(24):2536-43. DOl (http://dx.doi.org/10.1056/ NEJMoa0805715). PubMed (https://www.ncbi.nlm.nih. gov/entrez/query.fcgi?cmd=Retrieve\&db=PubMed\&lis t_uids=19516034\&dopt=Abstract).

5. Cao-Lormeau VM, Musso D. Emerging arboviruses in the Pacific. Lancet 2014 Nov;384(9954):1571-2. DOI (http:// dx.doi.org/10.1016/S0140-6736(14)61977-2). PubMed (https://www.ncbi.nlm.nih.gov/entrez/query.fcgi?cmd=Retrie ve\&db=PubMed\&list_uids=25443481\&dopt=Abstract).

6. Musso D, Nilles EJ, Cao-Lormeau VM. Rapid spread of emerging Zika virus in the Pacific area. Clin Microbiol Infect 2014 Oct;20(10):O595-6. DOI (http://dx.doi. org/10.1111/1469-0691.12707). PubMed (https://www.ncbi. nlm.nih.gov/entrez/query.fcgi?cmd=Retrieve \&db=PubMed\&l ist_uids=24909208\&dopt=Abstract).

7. World Health Organization. WHO statement on the first meeting of the International Health Regulations (2005) (IHR 2005) Emergency Committee on Zika virus and observed increase in neurological disorders and neonatal malformations. 2016. WHO: 2016. http://www.who.int/ mediacentre/news/statements/2016/1st-emergencycommittee-zika/en/. [Consulté le 5 octobre 2017].

8. Besnard M, Lastere S, Teissier A, Cao-Lormeau V, Musso D. Evidence of perinatal transmission of Zika virus, French Polynesia, December 2013 and February 2014. Euro Surveill 2014 Apr;19(13). DOI (http://dx.doi.org/10.2807/1560-7917. ES2014.19.13.20751). PubMed (https://www.ncbi.nlm.nih. gov/entrez/query.fcgi?cmd=Retrieve \&db=PubMed\&lis t_uids=24721538\&dopt=Abstract).

9. Oliveira Melo AS, Malinger G, Ximenes R, Szejnfeld PO, Alves Sampaio S, Bispo de Filippis AM. Zika virus intrauterine infection causes fetal brain abnormality and microcephaly: tip of the iceberg? Ultrasound Obstet Gynecol 2016 Jan;47(1):67. DOI (http://dx.doi.org/10.1002/uog.158310). PubMed (https://www.ncbi.nlm.nih.gov/entrez/query.fcgi?cmd=Retrie ve\&db=PubMed\&list_uids=26731034\&dopt=Abstract).
10. Atkinson B, Thorburn F, Petridou C, Bailey D, Hewson R, Simpson AJ et al. Presence and Persistence of Zika Virus RNA in Semen, United Kingdom, 2016. Emerg Infect Dis 2017 Apr;23(4):611-5. DOI (http://dx.doi.org/10.3201/ eid2304.161692). PubMed (https://www.ncbi.nlm.nih. gov/entrez/query.fcgi?cmd=Retrieve\&db=PubMed\&lis t_uids=27997333\&dopt=Abstract).

11. Musso D, Roche C, Robin E, Nhan T, Teissier A, CaoLormeau VM. Potential sexual transmission of Zika virus. Emerg Infect Dis 2015 Feb;21(2):359-61. DOI (http://dx.doi. org/10.3201/eid2102.141363). PubMed (https://www.ncbi. $\mathrm{nlm}$.nih.gov/entrez/query.fcgi?cmd=Retrieve \&db=PubMed\&l ist_uids=25625872\&dopt=Abstract).

12. Musso D, Nhan T, Robin E, Roche C, Bierlaire D, Zisou K et al. Potential for Zika virus transmission through blood transfusion demonstrated during an outbreak in French ynesia, November 2013 to February 2014. Euro Surveill 2014 Apr;19(14). DOI (http://dx.doi.org/10.2807/1560-7917. ES2014.19.14.20761). PubMed (https://www.ncbi.nlm.nih. gov/entrez/query.fcgi?cmd=Retrieve \&db=PubMed\&lis t_uids=24739982\&dopt=Abstract).

13. Herriman R. Transfusion-associated Zika virus reported in Brazil. Outbreak News Today. December 18, 2015. http:// outbreaknewstoday.com/transfusion-associated-zika-virusreported-in-brazil-76935/. [Consulté le 12 juin 2017].

14. Centers for Disease Control and Prevention. Zika virus. CDC 24/7;2017. https://www.cdc.gov/zika/transmission/index. html. [Consulté le 13 juin 2017].

15. Krow-Lucal ER, Biggerstaff BJ, Staples JE. Estimated Incubation Period for Zika Virus Disease. Emerg Infect Dis 2017 May;23(5):841-5. DOI (http://dx.doi.org/10.3201/ eid2305.161715). PubMed (https://www.ncbi.nlm.nih. gov/entrez/query.fcgi?cmd=Retrieve $\& \mathrm{db}=$ PubMed\&lis t_uids=28277198\&dopt=Abstract).

16. World Health Organization. Situation Report: Zika Virus Microcephaly Guillain Barre Syndrome. WHO: 10 March 2017. http://apps.who.int/iris/bitstream/10665/254714/1/ zikasitrep10Mar17-eng.pdf?ua=1 [Consulté le 12 juin 2017].

17. Reynolds MR, Jones AM, Petersen EE, Lee EH, Rice ME, Bingham A et al.; U.S. Zika Pregnancy Registry Collaboration. Vital Signs: Update on Zika Virus-Associated Birth Defects and Evaluation of All U.S. Infants with Congenital Zika Virus Exposure - U.S. Zika Pregnancy Registry, 2016. MMWR Morb Mortal Wkly Rep 2017 Apr;66(13):366-73. DOI (http://dx.doi. org/10.15585/mmwr.mm6613e1). PubMed (https://www. ncbi.nlm.nih.gov/entrez/query.fcgi?cmd=Retrieve\&db=PubM ed\&list_uids=28384133\&dopt=Abstract).

18. Shapiro-Mendoza CK, Rice ME, Galang RR, Fulton AC, VanMaldeghem K, Prado MV et al.; Zika Pregnancy and Infant Registries Working Group. Pregnancy Outcomes After Maternal Zika Virus Infection During Pregnancy - U.S. Territories, January 1, 2016-April 25, 2017. MMWR Morb Mortal Wkly Rep 2017 Jun;66(23):615-21. DOI (http://dx.doi. org/10.15585/mmwr.mm6623e1). PubMed (https://www. ncbi.nlm.nih.gov/entrez/query.fcgi?cmd=Retrieve\&db=PubM ed\&list_uids=28617773\&dopt=Abstract).

19. Duarte G, Moron AF, Timerman A, Fernandes CE, Mariani Neto C, Almeida Filho GL et al. Zika Virus Infection in 
Pregnant Women and Microcephaly. Rev Bras Ginecol Obstet 2017 May;39(5):235-48. DOl (http://dx.doi. org/10.1055/s-0037-1603450). PubMed (https://www.ncbi. $\mathrm{nlm}$.nih.gov/entrez/query.fcgi?cmd=Retrieve \&db=PubMed\&l ist_uids=28575919\&dopt=Abstract).

20. Fonseca K, Meatherall B, Zarra D, Drebot M, MacDonald $\mathrm{J}$, Pabbaraju $\mathrm{K}$ et al. First case of Zika virus infection in a returning Canadian traveler. Am J Trop Med Hyg 2014 Nov;91(5):1035-8. DOI (http://dx.doi.org/10.4269/ ajtmh.14-0151) PubMed (https://www.ncbi.nlm.nih.gov/ entrez/query.fcgi?cmd=Retrieve \&db=PubMed\&list_ uids=25294619\&dopt=Abstract)

21. Teale A, Payne M, England J, Morshed M, Hull M. Le virus Zika, un flavivirus émergent, identifié comme cause de fièvre et d'éruption cutanée chez un voyageur de retour d'Amérique centrale. Relevé des maladies transmissibles au Canada. 2016;42(3):68-71. http://www.phac-aspc.gc.ca/ publicat/ccdr-rmtc/16vol42/dr-rm42-3/assets/pdf/16vol42_3ar-04-fra.pdf

22. Statistique Canada. Enquête sur les voyages internationaux : questionnaires électronique et Enquête sur les départs aériens (EVI). Ottawa (ON); Statistique Canada: 2015. http://www23.statcan.gc.ca/imdb/p2SV_f. pl?Function=getSurvey\&SDDS=3152. [Consulté le 14 juillet 2017].

23. World Health Organization. Zika virus (ZIKV) classification table: Data as of 20 June 2017. WHO: 2017. http://apps. who.int/iris/bitstream/10665/255767/1/zika-classification20June17-eng.pdf?ua=1. [Consulté le 28 juillet 2017]

24. Pan American Health Organization. Web Plot Digitizer. [Online].; 2017. https://automeris.io/WebPlotDigitizer/. [Consulté le 6 juillet 2017].

25. Baud D, Gubler DJ, Schaub B, Lanteri MC, Musso D. An update on Zika virus infection. Lancet 2017 Nov;390(10107):2099-109. DOI (http://dx.doi.org/10.1016/ S0140-6736(17)31450-2) PubMed (https://www.ncbi.nlm. nih.gov/entrez/query.fcgi?cmd=Retrieve\&db=PubMed\&li st_uids=28647173\&dopt=Abstract).

26. Gouvernement du Canada. Virus Zika : Conseils à l'intention des voyageurs. 2017. https://travel.gc.ca/travelling/healthsafety/travel-health-notices/152

27. Groupe de travail sur Zika du Comité consultatif de la médecine tropicale et de la médecine des voyages (CCMTMV). Recommandations canadiennes pour la prévention et le traitement du virus Zika : mise à jour. Relevé des maladies transmissibles au Canada. 2016;42(5):114-25. https://www.canada.ca/content/dam/phac-aspc/migration/ phac-aspc/publicat/ccdr-rmtc/16vol42/dr-rm42-5/assets/ pdf/16vol42_5-ar-01-fra.pdf

28. Gouvernement du Canada. Recommandations sur la prévention et le traitement du virus Zika pour les professionnels de la santé au Canada. http:// canadiensensante.gc.ca/publications/diseases-conditionsmaladies-affections/committee-statement-treatmentprevention-zika-declaration-comite-traitement-prevention/ index-fra.php

29. Gouvernement du Canada. Pour les professionnels de la santé : virus Zika. 2017. https://www.canada.ca/fr/santepublique/services/maladies/virus-zika/pour-professionnelssante-virus-zika.html

30. Maxian O, Neufeld A, Talus EJ, Childs LM, Blackwood JC. Zika virus dynamics: When does sexual transmission matter? Epidemics. 2017 Jun; pii: S1755-4365(17)30109-3. DOI (https://doi.org/10.1016/j.epidem.2017.06.003). PubMed (https://www.ncbi.nlm.nih.gov/pubmed/28688996).

31. Oduyebo T, Polen KD, Walke HT, Reagan-Steiner S, Lathrop E, Rabe IB et al. Update: Interim Guidance for Health Care Providers Caring for Pregnant Women with Possible Zika Virus Exposure - United States (Including U.S. Territories), July 2017. MMWR Morb Mortal Wkly Rep 2017 Jul;66(29):781-93. DOI (http://dx.doi.org/10.15585/ mmwr.mm6629e1). PubMed (https://www.ncbi.nlm.nih. gov/entrez/query.fcgi?cmd=Retrieve \&db=PubMed\&lis t_uids=28749921\&dopt=Abstract).

32. Ogden NH, Fazil A, Safronetz D, Drebot MA, Wallace J, Rees EE et al. Risk of travel-related cases of Zika virus infection is predicted by transmission intensity in outbreak-affected countries. Parasit Vectors 2017 Jan;10(1):41. DOI (http:// dx.doi.org/10.1186/s13071-017-1977-z). PubMed (https:// www.ncbi.nlm.nih.gov/entrez/query.fcgi?cmd=Retrieve\&db= PubMed\&list_uids=28122631\&dopt=Abstract).

33. da Cruz Ferreira DA, Degener CM, de Almeida MarquesToledo C, Bendati MM, Fetzer LO, Teixeira CP et al. Meteorological variables and mosquito monitoring are good predictors for infestation trends of Aedes aegypti, the vector of dengue, chikungunya and Zika. Parasit Vectors 2017 Feb;10(1):78. DOI (http://dx.doi.org/10.1186/ s13071-017-2025-8). PubMed (https://www.ncbi.nlm.nih. gov/entrez/query.fcgi?cmd=Retrieve \&db=PubMed\&lis t_uids=28193291\&dopt=Abstract).

34. Agence de la santé publique du Canada. Virus Zika. Ottawa (ON); ASPC: 2017. https://www.canada.ca/fr/sante-publique/ services/maladies/virus-zika.html 


\section{Annexe 1 : Date du voyage selon l'état d'éclosion du virus Zika dans le pays de} destination, mai 2015 à juin $2017\left(\mathrm{~N}=493^{\mathrm{a}}\right)$

\begin{tabular}{|c|c|c|c|c|c|c|c|c|}
\hline Région & $\begin{array}{l}\text { Pays ou région } \\
\text { de voyage }\end{array}$ & $\mathrm{n}$ & $\begin{array}{c}\text { Nombre estimatif } \\
\text { de voyageurs } \\
\text { canadiens } \\
\text { (mai 2015 à } \\
\text { juin 2017) }\end{array}$ & $\begin{array}{c}\text { Taux } \\
\text { d'infection } \\
\text { approximatif } \\
\text { (pour } 100000 \\
\text { voyageurs) }\end{array}$ & $\begin{array}{l}\text { Nombre } \\
\text { total de cas } \\
\text { liés à des } \\
\text { voya-ges par } \\
\text { région }\end{array}$ & $\begin{array}{l}\text { Pourcentage de } \\
\text { cas liés à des } \\
\text { voyages par } \\
\text { région }\end{array}$ & $\begin{array}{c}\text { Nombre total } \\
\text { approximatif de } \\
\text { voyageurs vers } \\
\text { la région }\end{array}$ & $\begin{array}{c}\text { Taux } \\
\text { d'infection } \\
\text { approximatif } \\
\text { (pour } 100000 \\
\text { voyageurs) } \\
\text { vers la région }\end{array}$ \\
\hline \multirow{17}{*}{ Antilles } & $\begin{array}{l}\text { Antigua-et- } \\
\text { Barbuda }\end{array}$ & 4 & 102917 & 3,89 & \multirow{17}{*}{322} & \multirow{17}{*}{65,71} & \multirow{17}{*}{2897083} & \multirow{17}{*}{1,11} \\
\hline & Bahamas & 3 & 454583 & 0,66 & & & & \\
\hline & Barbade & 53 & 394375 & 13,44 & & & & \\
\hline & $\begin{array}{l}\text { Bonaire, Saint- } \\
\text { Eustache et } \\
\text { Saba }\end{array}$ & 4 & - & & & & & \\
\hline & \begin{tabular}{|l} 
Îles Vierges \\
britanniques
\end{tabular} & 4 & 52083 & 7,68 & & & & \\
\hline & $\begin{array}{l}\text { Antilles (île non } \\
\text { précisée) }\end{array}$ & 12 & - & - & & & & \\
\hline & Curaçao & 15 & - & - & & & & \\
\hline & $\begin{array}{l}\text { République } \\
\text { dominicaine }\end{array}$ & 40 & 1014167 & 3,94 & & & & \\
\hline & Grenade & 10 & 25208 & 39,67 & & & & \\
\hline & Guadeloupe & 5 & 46042 & 10,86 & & & & \\
\hline & Haïti & 19 & 82500 & - & & & & \\
\hline & Jamaïque & 78 & 461042 & 16,92 & & & & \\
\hline & Martinique & 7 & 9792 & 71,49 & & & & \\
\hline & Sainte-Lucie & 8 & 88958 & 8,99 & & & & \\
\hline & $\begin{array}{l}\text { Saint-Martin et } \\
\text { Sint Maarten }\end{array}$ & 17 & 17292 & 98,31 & & & & \\
\hline & $\begin{array}{l}\text { Saint-Vincent- } \\
\text { et-Grenadines }\end{array}$ & 8 & 17708 & 45,18 & & & & \\
\hline & \begin{tabular}{|l|} 
Trinité-et- \\
Tobago
\end{tabular} & 35 & 130417 & 26,84 & & & & \\
\hline $\begin{array}{l}\text { Amérique } \\
\text { du Nord }\end{array}$ & Mexique & 47 & 4012292 & 1,17 & 47 & 9,59 & 4012292 & 1,17 \\
\hline \multirow{7}{*}{$\begin{array}{l}\text { Amérique } \\
\text { centrale } \\
\text { (sans } \\
\text { précision) }\end{array}$} & $\begin{array}{l}\text { Amérique } \\
\text { centrale }\end{array}$ & 8 & - & & \multirow{7}{*}{76} & \multirow{7}{*}{15,51} & \multirow{7}{*}{780000} & \multirow{7}{*}{9,74} \\
\hline & Costa Rica & 15 & 362708 & 4,14 & & & & \\
\hline & El Salvador & 9 & 85208 & 10,56 & & & & \\
\hline & Guatemala & 10 & 58333 & 17,14 & & & & \\
\hline & Honduras & 4 & 138750 & 2,88 & & & & \\
\hline & Nicaragua & 29 & 62083 & 46,71 & & & & \\
\hline & Panama & 1 & 72917 & 1,37 & & & & \\
\hline \multirow{7}{*}{$\begin{array}{l}\text { Amérique } \\
\text { du Sud }\end{array}$} & Bélize & 1 & 198125 & 0,50 & \multirow{7}{*}{45} & \multirow{7}{*}{9,18} & \multirow{7}{*}{1082798} & \multirow{7}{*}{4,16} \\
\hline & Brésil & 4 & 203333 & 1,97 & & & & \\
\hline & Colombie & 17 & 187083 & 9,09 & & & & \\
\hline & Équateur & 3 & 71250 & 4,21 & & & & \\
\hline & Guyane & 14 & 135000 & 10,37 & & & & \\
\hline & Pérou & 1 & 274792 & 0,36 & & & & \\
\hline & Vénézuela & 5 & 13125 & 38,10 & & & & \\
\hline \multirow{3}{*}{ Autre } & Philippines & 1 & - & - & \multirow{3}{*}{3} & \multirow{3}{*}{-} & & \\
\hline & Thaïlande & 1 & - & - & & & & \\
\hline & Vietnam & 1 & - & - & & & & \\
\hline \multicolumn{2}{|l|}{ TOTAL } & 493 & s/o & s/o & 493 & 100 & 8772083 & 5,59 \\
\hline
\end{tabular}

